\title{
The Influence of China's COVID-19 Treatment Policy on the Sustainability of Its Social Health Insurance System
}

\author{
Fei Zuo iD' \\ Shaoguo Zhai ${ }^{2}$ \\ 'Department of Finance, Economics and \\ Management School, Northwest \\ University, Xi'an, Shaanxi Province, \\ People's Republic of China; ${ }^{2}$ Department \\ of Social Security, Public Management \\ School, Northwest University, Xi'an, \\ Shaanxi Province, People's Republic of \\ China
}

Background: While past experiences show that a health system financing mechanism can support resilience to shocks, the impact on the sustainability of the financing system is exceptionally important considering the magnitude of the COVID-19 pandemic. The role of Social Health Insurance (SHI) in responding to the pandemic brings about an influence on insurance system sustainability. This study investigates the impact of China's COVID-19 treatment policy on the sustainability of its SHI system, explores influences of the policy on Wuhan's system, and discusses the effects of an assumed equivalent emergency on SHI funds for five other provincial capital cities in China.

Methods: The study was conducted using pay-as-you-go actuarial models of Urban Employee Basic Medical Insurance (UEBMI) and Urban and Rural Residents Basic Medical Insurance (URRBMI) funds, which constitute China's basic health insurance system. Current and accumulated balances of the funds in 2020 are predicted and utilized to measure the sustainability of health insurance funds during emergencies.

Results: The findings suggest a disparity in the capacities of insurance schemes and localities. If the surplus before 2018 is not considered, it is likely that the URRBMI fund of Wuhan would suffer a deficit, whereas the UEBMI would retain a considerable surplus. To maintain the current actuarial balance of the URRBMI fund, coverage for ordinary inpatient and outpatient expenses would have to be significantly reduced in Wuhan, potentially affecting enrollees' wellbeing. A similar situation may occur in three other cities, some with underdeveloped economies and lower per capita income are likely to be encountered with worse situation than Wuhan.

Conclusion: Concerning fragmentation of China's SHI system, to strengthen longer-term preparedness to manage future emergencies, this study suggests the integration of insurance schemes and provincial pooling, fund balance adjusting and an emergency safety net are also advised. All options call for more public health investments.

Keywords: public health emergency, COVID-19 pandemic, public health insurance, sustainability, disparity

\section{Introduction}

The COVID-19 pandemic has precipitated unprecedented economic, social and health crisis worldwide, raising reflection on underlying factors that distinct countries in their response. One of the considerations lies in financing, which has been identified as a core aspect enabling or hindering health systems' capacity responding to past shocks. ${ }^{1}$ In China, where confirmed cases were first reported, Social Health Insurance (SHI) was placed as the first firewall in addressing the treatment
Correspondence: Fei Zuo

Department of Finance, Northwest

University, No. I, Xuefu Road, Xi'an,

Shaanxi Province, People's Republic of

China

Tel +86 I53-3907-9756

Email grace.fiz@nwu.edu.cn 
cost, with the out-of-pocket (OOP) payment furthered covered fiscally. ${ }^{2}$ According to the official report "Fighting COVID-19: China in Action", 67\% of treatment costs have been reimbursed by SHI funds. ${ }^{3}$ For China, the accountability of financing mechanism may not seem a big problem at first glance concerning the proportion of confirmed cases in the population $(0.088 \%)$, yet taking into account the fragmented insurance systems for urban employees and other residents, inadequate input from government, ${ }^{4}$ regionally-pooled nature of funds and $100 \%$ hospitalization of COVID-19 confirmed patients, the effect on the sustainability of SHI system is of much concern, especially for regions where cases were concentrated, ie, Wuhan city and Hubei province.

Not much research has been done up to now on the impact of a sudden public health emergency on financing, potentially because the world has not witnessed such a widespread pandemic within a short time. For China, although there are already plenty of studies on the sustainability of SHI, most of them focus on the effect of day-to-day, chronic challenges, including aging, climate change, pollution, and policy change. This article aims to investigate the impact of China's COVID-19 treatment policy on the sustainability of its SHI system, particularly, it seeks to explore the influence of the policy on city Wuhan's system, as well as on five other provincial capital cities in the country, under the presumed condition that such event broke out in these cities. The cities sampled are city $\mathrm{C}$ with approximately the same per capita disposable income as Wuhan, City H and G with much higher income, and city $\mathrm{N}$ and $\mathrm{X}$, whose income are among the lowest in China.

For countries like China that address SHI as the fundamental infrastructure in their pursuing of universal health coverage, the performance and sustainability of insurance system will to a large extent determine the resilience of their health systems to withstand future crisis, then investigation on the impact on China's health insurance system will not only help to evaluate the economic outcome and system accountability of the nation but also promote wider reflection on what can be done on sustainability and equitability of health insurance system to cope with large-scale health emergency in the time ahead.

\section{Methods}

The selection of the research method is closely related to China's institutional background. The country's healthcare system under the planned economy era provided nearly universal coverage, with separate schemes for government officials and staff, state-owned enterprises (SOEs), employees, and rural citizens. From the end of the 1980s, mass bankruptcies of SOEs occurred as a result of the market transition, subsequent retrenchments in the urban health sector, along with the breakdown of communist communities in rural areas, undermined the institutional and economic foundations of the previous system and led to the development of a mini welfare state. ${ }^{5}$ Old insurance schemes were either dismantled or substantially weakened. By 1998, insurance coverage had fallen to 5 and $38 \%$ in rural and urban areas, respectively. ${ }^{6}$ Further impacted by the significant inflation of medical costs, ${ }^{7}$ the Chinese system was considered by the World Health Organization (WHO) as among the least equitable in the world by $2000{ }^{8}$

In 2009, China launched its comprehensive health reform, aiming to establish a basic healthcare system covering the entire population by 2020 . While overall coverage reached $95 \%$ by 2019 , the fragmented SHI system remained because of the country's historically decentralized and incremental approach toward universal coverage $;{ }^{9,10}$ the separate schemes of the Urban Employee Basic Medical Insurance (UEBMI), Urban Resident Basic Medical Insurance (URBMI), and New Cooperative Medical Insurance (NCMI) vary greatly in terms of financing and benefits. The Chinese government announced its blueprint for integrating the urban and rural resident schemes in early 2016. URBMI and NCMI were gradually consolidated into Urban and Rural Residents Basic Medical Insurance (URRBMI) in many parts of the country, including the cities sampled in this research. The systemic fragmentation is further reflected in the regionally pooled nature of insurance funds. Pooled at the municipal and even county levels, there were roughly 2852 NCMI units, 333 UEBMI units, and 333 URBMI units by $2015,{ }^{11}$ and significant differences exist across schemes and regions.

To investigate COVID-19's pressure on health insurance funds (or that of public health emergencies of the same magnitude), respective actuarial models are constructed for URRBMI and UEBMI. Considering the fact that SHI schemes in China are defined benefit schemes based on pay-as-you-go (PAYG) system, actuarial models constructed are all PAYG models. The current and accumulated balances in the sample period are predicted from the models and utilized to measure the effects on the sustainability of the SHI fund. Here, the current balance is obtained from the difference between fund income and expenditures in the current period, and the accumulated 
balance is the sum of the current balance and the accumulated balance of the past year. Considering that the integration of URBMI and NCMI into URRBMI was widely accomplished only after 2017, 2018 was chosen as the starting year in this simulation, and no management cost is considered, according to China's Social Security Act.

\section{Actuarial Model}

\section{Actuarial Model of the URRBMI Fund}

The URRBMI fund is financed by both individual contributions and government subsidies at a 30-70 split, with slight differences between localities. ${ }^{12}$ Total fund income of city $i$ in year $t$ (denoted as $A I_{i, t}$ ) equals the product of: the total number insured in city $i\left(A R P_{i, t}\right)$, per capita contributions in that year $\left(\overline{P I}_{i, t}\right.$, released by healthcare security administrations of sample cities), and the collection rate $\left(\beta_{A}\right)$, which is the number of enrollees who contributed relative to those who were supposed to pay the premium. As Equation (1) shows:

$$
A I_{i, t}=A R P_{i, t} \times \overline{P I}_{i, t} \times \beta_{A}{ }^{(t=2018,2019,2020)}
$$

Besides expenditures for reimbursement of inpatient expenses, there are pooled funds for reimbursement of outpatient expenses in all sample cities. In 2018 and 2019, the total expenditures of the URRBMI fund $\left(A C_{i, t}\right)$ included the reimbursement for outpatient $\left(T O C_{i, t}^{A}\right)$ and inpatient $\left(T I C_{i, t}^{A}\right)$ expenses, as follows:

$$
\begin{aligned}
A C_{i, t} & =\beta_{A} \times\left(\operatorname{TOC}_{i, t}^{A}+\operatorname{TIC}_{i, t}^{A}\right) \\
& =\beta_{A} \times\left[\begin{array}{l}
\left(A R P_{i, t} \times O_{i, t}^{A} \times P O C_{i, t}^{A} \times k_{i, t}^{A}\right) \\
+\left(A R P_{i, t} \times I_{i, t}^{A} \times P I C_{i, t}^{A} \times c_{i, t}^{A} \times r_{i, t}^{A}\right)
\end{array}\right]^{(t=2018,2019)}
\end{aligned}
$$

In Equation (2), $T O C_{i, t}^{A}$ is calculated as the product of: $A R P_{i, t}$, the number of outpatient treatments per enrollee $\left(O_{i, t}^{A}\right)$, the average outpatient expenses per treatment $\left(P O C_{i, t}^{A}\right)$, and the general reimbursement rate for outpatient expenses $\left(k_{i, t}^{A}\right)$. Meanwhile, $T I C_{i, t}^{A}$ is calculated as the product of: $A R P_{i, t}$, the number of hospitalizations per enrollee $\left(I_{i, t}^{A}\right)$, the average inpatient cost per hospitalization $\left(P I C_{i, t}^{A}\right)$, the coverage scope of the URRBMI fund $\left(c_{i, t}^{A}\right)$, and the reimbursement rate for inpatient expenses $\left(r_{i, t}^{A}\right)$. The coverage scope refers to the proportion of inpatient expenses that are within the official directory of UEBMI, and $r_{i, t}^{A}$ is the reimbursement rate for expenses that are within the directory.
From 2017, to strengthen control of excessive medical expenses, China implemented a form of fund budget management characterized by paying based on Diagnosis Related Groups rather than as Fee for Service. All cities studied in this research were included in the experimental cities in this implementation. It is generally believed that medical expenses decreased because of this policy, thus, fund reimbursement expenditures for ordinary expenses are reduced in this research by the average proportion as calculated by two widely cited Chinese studies on the impact of payment reform on fund expenditures. ${ }^{13,14}$ The same practice is used in the calculation of UEBMI fund expenditures.

When $t$ equals 2020, fund expenditures also include the reimbursement for hospitalization expenses caused by COVID-19 (denoted as $\operatorname{Corexp}_{A}$ ), which equals the product of the number of confirmed patients in the URRBMI system $\left(\mathrm{Cor}_{A}\right)$ and per patient treatment costs $(\overline{\text { Corexp }})$, as follows:

$$
\begin{aligned}
A C_{i, t} & =\beta_{A} \times\left[\left(\operatorname{TOC}_{i, t}^{A}+T I C_{i, t}^{A}\right)+\operatorname{Corexp}_{A}\right] \\
& =\beta_{A} \times\left[\left(\operatorname{TOC}_{i, t}^{A}+T I C_{i, t}^{A}\right)+\operatorname{Cor}_{A} \times \overline{\operatorname{Corexp}} \times r_{i, t}^{A}\right]^{(t=2020)}
\end{aligned}
$$

The coverage scope is set to one according to China's treatment policy that drugs and services in the "COVID19 Diagnosis and Treatment Plan" should all be included in the SHI directory. According to China's "Statistical Bulletin on the Development of Medical Security" (hereafter referred to as the "Bulletin") that was released in 2019, $95 \%$ of all citizens had basic health insurance coverage, so it is assumed that the same proportion of COVID-19 patients were insured. Since there is no publicly available information about the number of COVID-19 patients belonging to different schemes, this research estimates the number of patients belonging to the two schemes according to the ratio of enrollees in the two schemes in Wuhan, based on the assumption that COVID-19 patients are uniformly distributed in the population.

Considering income and expenditures, the current balance $\left(A T_{i, t}\right)$ and accumulated balance $\left(A F_{i, t}\right)$ of the URRBMI fund are calculated as:

$$
\begin{gathered}
A T_{i, t}=A I_{i, t}-A C_{i, t} \\
A F_{i, t}=A T_{i, t}\left(1+A_{1}\right)+A F_{i, t-1}\left(1+A_{2}\right)
\end{gathered}
$$

In Equations 4 and 5, $A_{1}$ and $A_{2}$ are the interest rates for the current and accumulated balances, respectively; 
according to China's Social Security Act, these values are set to the current deposit rate $(0.35 \%)$, and the three-month lump-sum deposit and withdrawal rate $(1.1 \%)$. Accumulated balances are utilized when there is no current balance.

\section{Actuarial Model of the UEBMI Fund}

All urban employees in China are required to join the UEBMI scheme by paying $2 \%$ of their payroll income, which is matched by an employer contribution of $6-$ $10 \%{ }^{15}$ Fund income is divided into personal accounts and one pooling account. The pooling account, which is from $60-70 \%$ of the employer's payment, is the main source of reimbursement for inpatient and outpatient expenses from chronic and catastrophic diseases, and accounts for over $97 \%$ of the expenses covered by health insurance, according to the 2018 "Bulletin". Therefore, the income and expenditures in the investigation of UEBMI funds refer to the pooling fund, and the actuarial model is as follows:

$$
\begin{aligned}
B I_{i, t}= & B R P_{i, t} \times W_{i, t} \times \gamma_{i, t} \times \theta_{i, t} \\
& \times \beta_{B}(t=2018,2019,2020)
\end{aligned}
$$

Total UEBMI fund income for city $i$ in year $t\left(B I_{i, t}\right)$ is the product of: the total number insured in UEBMI $\left(B R P_{i, t}\right)$; the social average wage $\left(W_{i, t}\right)$, which is the payroll income stated in law and published by the local statistical department; the proportion of the annual payment base that employers are supposed to pay $\left(\gamma_{i, t}\right)$; the proportion of fund income that is deposited in the pooling account $\left(\theta_{i, t}\right)$; and the collection rate for the UEBMI fund $\left(\beta_{B}\right)$.

Fund expenditures $\left(B C_{i, t}\right)$ are the aggregation of outpatient $\left(T O C_{i, t}^{B}\right)$ and inpatient compensation expenditures $\left(T I C_{i, t}^{B}\right),{ }^{16}$ multiplied by the collection rate, as follows:

$$
\begin{aligned}
B C_{i, t} & =\beta_{B} \times\left(\operatorname{TOC}_{i, t}^{B}+\operatorname{TIC}_{i, t}^{B}\right) \\
& =\beta_{B} \times\left[\begin{array}{l}
\left(O C_{i, t}^{B} \times k_{i, t}^{B}\right) \\
+\left(B R P_{i, t} \times I_{i, t}^{B} \times P I C_{i, t}^{B} \times c_{i, t}^{B} \times r_{i, t}^{B}\right)
\end{array}\right]\left(_{(t=2018,2019)}\right.
\end{aligned}
$$

In Equation 7, the product of overall outpatient expense before reimbursement $\left(O C_{i, t}^{B}\right)$ and the coverage rate for outpatient expenses $\left(k_{i, t}^{B}\right)$ gives us $T O C_{i, t}^{B}$. Meanwhile, $T I C_{i, t}^{B}$ is calculated as the product of: $B R P_{i, t}$, the number of hospitalizations per UEBMI enrollee $\left(I_{i, t}^{B}\right)$, the average inpatient cost per hospitalization $\left(P I C_{i, t}^{B}\right)$, the coverage scope of the UEBMI fund $\left(c_{i, t}^{B}\right)$, and the reimbursement rate for inpatient expenses $\left(r_{i, t}^{A}\right)$.

When it comes to 2020, total expenditures further include reimbursement expenditures of the UEBMI fund for COVID-19 patients $\left(\operatorname{Corexp}_{B}\right)$ :

$$
\begin{aligned}
B C_{i, t} & =\beta_{B} \times\left(\operatorname{TOC}_{i, t}^{B}+\operatorname{TOC}_{i, t}^{B}+\operatorname{Corexp}_{B}\right) \\
& =\beta_{B} \times\left[\begin{array}{l}
\left(\operatorname{TOC}_{i, t}^{B}+T O C_{i, t}^{B}\right) \\
+\operatorname{Cor}_{B} \times \overline{\operatorname{Corexp}} \times r_{i, t}^{B}
\end{array}\right] \quad{ }_{(t=2020)}
\end{aligned}
$$

where $\operatorname{Cor}_{B}$ is the number of confirmed patients in the UEBMI system, while $r_{i, t}^{B}$ is the reimbursement rate for the UEBMI fund (with coverage scope equal to 1 ).

Equations 9 and 10 give the current balance $\left(B T_{i, t}\right)$ and accumulated balance $\left(B F_{i, t}\right)$ of the UEBMI pooling fund:

$$
\begin{gathered}
B T_{i, t}=B I_{i, t}-B C_{i, t} \\
B F_{i, t}=B T_{i, t}\left(1+A_{1}\right)+B F_{i, t-1}\left(1+A_{2}\right)
\end{gathered}
$$

\section{Parameters}

Projections of the Insured Population and Its Growth Data on the insured population for 2018-2019 are from the "Statistics Bulletin of Economy and Social Development" for the sample cities, released by the local governments. The 2020 data have not been released, so they are projected using the average annual growth rate of this variable from 2015 to 2019. Data on the collection rate is from the 2018 "Bulletin" and is assumed to be unchanged during the sample period.

\section{Projection of Medical Expenses and Their Growth}

The per enrollee number of hospitalizations, average inpatient cost per URRBMI and UEBMI enrollee hospitalization, and the per URRBMI enrollee number of outpatient treatments are all obtained from the 2018 and 2019 issues of the "Bulletin". It is assumed that the per enrollee number of hospitalizations and number of outpatient treatments in 2020 are the same as that of 2019, while the average inpatient cost per hospitalization for UEBMI enrollees is predicted using the average annual growth rate of the variable for 2015-2019. The average outpatient cost per time of URRBMI enrollees in 2018-2020 is predicted using 2017 data, and the average annual growth rate of outpatient costs from 2013 to 2017 are all obtained from the China Health Statistics Yearbook released by the National Health Commission of China. 


\section{Coverage Scope and Reimbursement Rate of Hospitalization Expenses}

According to the 2018 and 2019 "Bulletin", for the URRBMI fund, the reimbursement rates for hospitalization expenses that are within the official directory were 65.6 and $68.8 \%$ in 2018 and 2019, respectively. Furthermore, 56.1 and $59.7 \%$ of total hospitalization expenses were paid by the URRBMI fund, implying that the coverage scope of the fund for each year was $85.52 \%$ and $86.77 \%$, respectively. As for the UEBMI fund, the reimbursement rates for hospitalization expenses within the official directory were 81.6 and $85.8 \%$ in 2018 and 2019 , respectively, and 71.8 and $75.6 \%$ of total hospitalization expenses were paid by the UEBMI pooling fund in each year. These national averages are used in the following calculation, except for cities $\mathrm{H}$ and $\mathrm{G}$, which clearly disclosed the true reimbursement rates for the URRBMI and UEBMI funds in 2018-2020. Furthermore, on June 17, 2020, the National Healthcare Security Administration (NHSA), the Ministry of Finance, and the State Taxation Administration jointly issued a notice on the implementation of the URRBMI scheme in 2020, which stated that reimbursement rates for hospitalization expenses within the official directory would reach $70 \%$ in 2020. Accordingly, assuming that the coverage scope in 2020 is consistent with that in 2019 , the national average reimbursement rate for hospitalization expenses for URRBMI enrollees was predicted to be $60.74 \%$ in 2020 (the actual rate has not been released by the time this article was finished).

\section{Results}

\section{Scenarios}

In this analysis, the hospitalization costs associated with the COVID-19 pandemic were calculated using the per capita cost disclosed as 23,000 yuan (RMB) in the official report "Fighting COVID-19: China in Action." As for the number of COVID-19 patients and the health insurance system to which they belong, in accordance with the $95 \%$ coverage rate, 47,823 of 50,340 confirmed patients in Wuhan participated in SHI (numbers calculated as of the end of 2020). In line with the ratio of UEBMI to URRBMI numbers of enrollee by the end of 2019 in Wuhan (4.6643 million/4.7076 million), approximately 23,797 of the 47,823 patients belonged to the UEBMI system, and 24,026 belonged to the URRBMI system. Therefore, the total treatment cost to be compensated is estimated as
547.33 million yuan and 552.60 million yuan in the UEBMI and URRBMI schemes, respectively. These values are used in the present analysis as the total hospitalization costs resulting from the COVID-19 pandemic (or an equivalent public health emergency) in Wuhan and other sample cities.

According to the literature, ${ }^{17}$ the reimbursement rates for outpatient expenses that are within the official directory are generally between $50 \%$ and $60 \%$. Considering the overall low level of URRBMI funding, the fact that the outpatient pooling fund mainly covers primary medical services and generally has deductibles and capping payments, this study considers three scenarios of outpatient reimbursement rates as being $10 \%, 20 \%$, and $30 \%$. As for UEBMI, which generally has a higher level of protection, the overall compensation ratio of outpatient expenditures is assumed to be $50 \%{ }^{18-21}$ Investigations under various circumstances can provide a better understanding of the sensitivity of these parameter settings.

\section{Impact of a Public Health Emergency on the Sustainability of the UEBMI Fund}

The results of the current and accumulated balances of the UEBMI fund in 2020 under the influence of the COVID19 pandemic (or a health emergency of the same magnitude) are shown in Table 1 (see our Supplementary Data for the Calculation Process). All sample cities except City $\mathrm{X}$ hold a significantly higher balance than the average for the past two years, suggesting that most cities have been capable of withstanding the shock of COVID-19. Under the relatively generous assumptions used here (an outpatient cost reimbursement rate of $50 \%$ and an actual hospitalization reimbursement rate of 71.8-85.5\%), the UEBMI fund in Wuhan is predicted to have a current balance of 6.36 billion yuan and an accumulated balance of 17.45 billion yuan. City C, which has approximately the same per capita disposable income as Wuhan, is expected to have a current balance of 1.39 billion yuan and an accumulated balance of 3.87 billion yuan. Cities $G$ and $\mathrm{H}$, whose per capita disposable incomes are among the top ten in China, will possess a current balance as high as 20.12 and 29.06 billion yuan, respectively, and an accumulated balance of 50.02 and 74.48 billion yuan, respectively. Finally, Cities N and X, whose per capita disposable incomes are among the lowest, also are not expected to suffer deficits; although their balances are lower compared to past years, they still maintain current balances of 
Table I Current and Accumulated Balance of UEBMI Pooling Fund Under Public Health Emergency (Ten Thousand RMB Yuan)

\begin{tabular}{|l|l|c|c|}
\hline City & Year & Current Balance & Accumulated Balance \\
\hline Wuhan & 2018 & $501,280.96$ & $503,035.44$ \\
& 2019 & $584,137.37$ & $1,094,750.68$ \\
& 2020 & $636,191.35$ & $1,745,210.96$ \\
\hline City C & 2018 & $99,236.56$ & $99,583.89$ \\
& 2019 & $143,441.67$ & $244,623.02$ \\
& 2020 & $139,141.54$ & $386,942.41$ \\
\hline \multirow{2}{*}{ City G } & 2018 & $1,252,736.68$ & $1,257,121.26$ \\
& 2019 & $1,673,464.67$ & $2,950,271.38$ \\
& 2020 & $2,012,451.12$ & $5,002,219.06$ \\
\hline \multirow{2}{*}{ City H } & 2018 & $1,994,761.72$ & $2,001,743.39$ \\
& 2019 & $2,449,461.97$ & $4,481,797.64$ \\
& 2020 & $2,906,246.94$ & $7,447,516.23$ \\
\hline \multirow{2}{*}{ City N } & 2018 & $165,897.55$ & $166,478.19$ \\
& 2019 & $182,263.61$ & $351,210.98$ \\
& 2020 & $165,521.57$ & $521,175.19$ \\
\hline \multirow{2}{*}{ City X } & 2018 & $37,752.71$ & $37,884.85$ \\
& 2019 & $50,724.42$ & $89,203.54$ \\
& 2020 & $21,214.07$ & $111,473.09$ \\
\hline
\end{tabular}

212.14 million yuan for City $\mathrm{X}$ and 1.66 billion yuan for City N, and accumulated balances of 1.11 and 5.21 billion yuan for Cities $\mathrm{X}$ and $\mathrm{N}$, respectively.

\section{Impact of a Public Health Emergency on the Sustainability of the URRBMI Fund}

The current and accumulated balances of the URRBMI fund in 2020 under the impact of the COVID-19 pandemic (or a public health emergency of the same magnitude) are estimated and shown in Table 2 (see supplementary materials for the calculation process). The balances in 2020 are expected to decline significantly compared to the past two years. Wuhan's URRBMI fund are expected to suffer current deficits under two of the three scenarios, with the deficit size being 185.52 and 409.33 million yuan in Scenarios 2 and 3, respectively; however, current deficits can still be made up with the accumulated balance.

This article further calculates the critical reimbursement rate for the Wuhan URRBMI fund to maintain an actuarial balance, as shown in Table 3. In 2020, when the reimbursement rate for outpatient costs is fixed at $20 \%$, if

Table 2 Current and Accumulated Balance of URRBMI Fund Under Public Health Emergency (Ten Thousand RMB Yuan)

\begin{tabular}{|c|c|c|c|c|c|c|c|}
\hline \multirow[t]{2}{*}{ City } & \multirow[t]{2}{*}{ Year } & \multicolumn{2}{|c|}{ Scenario I } & \multicolumn{2}{|c|}{ Scenario 2} & \multicolumn{2}{|c|}{ Scenario 3} \\
\hline & & $\begin{array}{l}\text { Current } \\
\text { Balance }\end{array}$ & $\begin{array}{c}\text { Accumulated } \\
\text { Balance }\end{array}$ & $\begin{array}{l}\text { Current } \\
\text { Balance }\end{array}$ & $\begin{array}{c}\text { Accumulated } \\
\text { Balance }\end{array}$ & $\begin{array}{l}\text { Current } \\
\text { Balance }\end{array}$ & $\begin{array}{c}\text { Accumulated } \\
\text { Balance }\end{array}$ \\
\hline \multirow[t]{3}{*}{ Wuhan } & 2018 & $85,966.26$ & $86,267.14$ & $68,557.52$ & $68,797.47$ & $51,148.78$ & $51,327.80$ \\
\hline & 2019 & $46,003.82$ & $|33,380.9|$ & $24,863.01$ & $94,504.28$ & 3722.20 & $55,627.64$ \\
\hline & 2020 & 3828.35 & $138,689.85$ & $-18,552.58$ & $76,991.24$ & $-40,933.5$ I & $15,306.04$ \\
\hline \multirow[t]{3}{*}{ City C } & 2018 & $54,791.35$ & 54,983.II & $31,154.58$ & $31,263.62$ & 7517.82 & 7544.13 \\
\hline & 2019 & $34,706.90$ & $90,416.30$ & 5956.20 & $37,584.57$ & $-22,794.49$ & $-15,167.38$ \\
\hline & 2020 & 1324.16 & $92,739.68$ & $-29,373.14$ & 8624.86 & $-60,070.45$ & $-60,070.45$ \\
\hline \multirow[t]{3}{*}{ City G } & 2018 & $59,484.89$ & $59,693.09$ & $39,263.46$ & $39,400.88$ & $19,042.03$ & $19,108.68$ \\
\hline & 2019 & || $3,93 \mid .26$ & $174,679.73$ & $87,938.70$ & $128,080.78$ & $61,946.15$ & $81,481.83$ \\
\hline & 2020 & $115,232.55$ & $292,237.07$ & $86,191.26$ & $215,982.60$ & $57,149.97$ & $139,728.13$ \\
\hline \multirow[t]{3}{*}{ City H } & 2018 & $217,849.66$ & $218,612.14$ & $202,984.88$ & $203,695.33$ & $188,120.10$ & $188,778.52$ \\
\hline & 2019 & $185,338.90$ & $407,004.46$ & $167,356.98$ & $373,878.70$ & $149,375.06$ & $340,752.95$ \\
\hline & 2020 & $142,889.16$ & $554,870.78$ & $123,970.63$ & $502,395.89$ & $105,052.09$ & $449,921.01$ \\
\hline \multirow[t]{3}{*}{ City $\mathbf{N}$} & 2018 & $52,328.94$ & $52,512.09$ & $38,378.60$ & $38,5 \mid 2.92$ & $24,428.25$ & $24,5 \mid 3.75$ \\
\hline & 2019 & $36,856.04$ & $90,074.76$ & $19,620.08$ & $58,625.32$ & 2384.13 & $27,175.88$ \\
\hline & 2020 & -36.16 & $91,029.42$ & $-18,594.83$ & $40,675.36$ & $-37,|53.5|$ & -9678.69 \\
\hline \multirow[t]{3}{*}{ City $X$} & 2018 & $21,588.29$ & $21,663.85$ & $16,808.16$ & $16,866.99$ & $12,028.03$ & $12,070.12$ \\
\hline & 2019 & $18,134.96$ & $40,100.58$ & $12,230.30$ & $29,325.63$ & 6325.65 & $18,550.69$ \\
\hline & 2020 & $-11,897.33$ & $28,644.36$ & $-18,256.09$ & $11,392.13$ & $-24,614.85$ & -5860.11 \\
\hline
\end{tabular}


Table 3 Critical Reimbursement Rate for Wuhan URRBMI Fund to Maintain Actuarial Balance

\begin{tabular}{|c|c|c|}
\hline Year & $\begin{array}{c}\text { Critical Reimbursement } \\
\text { Rate for Inpatient Cost } \\
\text { (\%) }\end{array}$ & $\begin{array}{c}\text { Critical Reimbursement } \\
\text { Rate for Outpatient Cost } \\
\text { (\%) }\end{array}$ \\
\hline 2018 & $84.46 \%$ & $59.38 \%$ \\
2019 & $74.78 \%$ & $31.76 \%$ \\
$\mathbf{2 0 2 0}$ & $65.68 \%$ & $11.71 \%$ \\
\hline
\end{tabular}

the current actuarial balance is to be maintained after reimbursement for COVID-19 treatment costs in 2020 and with an inpatient cost reimbursement rate of $60.74 \%$, compensation for ordinary inpatient costs can only be $65.68 \%$, at most; in 2018 and 2019, the critical rates were $84.46 \%$ and $74.48 \%$, respectively. Similarly, if the reimbursement rate for inpatient costs is fixed at $60.74 \%$, as shown in the actuarial model, and compensation for COVID-19 patients is handled at the same rate, the 2020 outpatient reimbursement rate can only be $11.71 \%$; in 2018 and 2019, the critical rates amounted to $59.38 \%$ and $31.76 \%$, respectively. In general, to maintain actuarial balance, critical reimbursement rates for inpatient and outpatient costs in Wuhan in 2020 will have to be significantly lower than for past two years, further highlighting the influence of the COVID-19 pandemic.

What happens if a pandemic of the same magnitude occurs in other sample cities? The impact on the URRBMI fund for City $\mathrm{C}$ is similar to that of Wuhan; current deficits will occur in two of the three scenarios and will be the highest among all cities with deficits. Furthermore, if the accumulated balance before 2018 is not considered, there will be a shortage of 600.7 million yuan in the accumulated balance in Scenario 3. Cities H and G will not have current deficits under all scenarios, City $\mathrm{G}$ will maintain a current balance of 571.50 million-1.15 billion yuan and an accumulated balance of 1.40 billion-2.92 billion yuan. City $\mathrm{H}$, which is the best performer among the six sample cities, will possess a current balance of 1.05 billion1.43 billion yuan and an accumulated balance of 4.50 billion-5.55 billion yuan, indicating that Cities $\mathrm{H}$ and $\mathrm{G}$ hold strong risk tolerance.

In sharp contrast to Cities $\mathrm{H}$ and $\mathrm{G}$, Cities $\mathrm{N}$ and $\mathrm{X}$ are predicted to experience current deficits under all scenarios. The current deficit of City $\mathrm{N}$ can amount to 371.53 million yuan, and the accumulated balance will have a shortage of 96.79 million yuan under Scenario 3. Meanwhile, the current deficit of City X will be 1.19 billion-2.46 billion yuan, and the accumulated balance shortage under Scenario 3 will reach 58.60 million yuan. In terms of the 2020 balance compared with that of previous years, with the exceptions of Cities G and H, the 2020 current and accumulated balances of the sample cities, including Wuhan, are expected to be significantly lower than the average of the past two years.

This research further calculated the ratio of per capita financing of the URRBMI fund in the four deficit cities under actuarial balanced conditions relative to the actual financing level (Table 4). Under two scenarios with deficits, the per capita financing of Wuhan must be 1.05 to 1.11 times the original level. The ratios for Cities $\mathrm{C}, \mathrm{N}$, and $X$ are $1.07-1.15$ times, $1.00-1.14$ times, and 1.10-1.20 times the original levels, respectively.

\section{Discussion}

The results of this study indicate that, if the deferred characteristics of health insurance expenditures are not considered, meaning patients with other diseases might postpone their hospitalization during the outbreak based on their risk perception or cultural factors, ${ }^{22-25}$ moreover, if the surplus before 2018 is not considered, it is very likely that Wuhan and three of the other sample cities' URRBMI funds will hold current deficits. Still, impacts on the health insurance fund might be greater as a result of the following factors.

First, it was made clear in China's policy that medical expenses of suspected COVID-19 patients are also covered by health insurance, which is not considered due to the lack of data on total patient numbers and average costs. Second, it is generally believed that the insured's demand for medical treatment will gradually increase, yet since there is no publicly available information, the number of hospitalizations and the hospitalization costs for SHI enrollees in 2019 are still used in the simulations of the fund balances in 2020. Third, the analysis assumes that all patients treated in Wuhan participate in health insurance in

Table 4 The Ratio of per Capita Financing of URRBMI Fund Relative to Original Level in Four Deficit Cities Under Actuarial Balance in 2020 Current Period

\begin{tabular}{|l|c|c|c|}
\hline City & Scenario I & Scenario 2 & Scenario 3 \\
\hline Wuhan & - & 1.0515 & 1.1136 \\
City C & - & 1.0743 & 1.1519 \\
City N & 1.0001 & 1.0740 & 1.1479 \\
City X & 1.0981 & 1.1505 & 1.2029 \\
\hline
\end{tabular}


Wuhan, but there are actually patients treated in other districts. The policy is that COVID-19 patients confirmed in districts other than their insurance-participating city should be treated before expenses are settled with their local SHI agencies. According to a government publication issued at the end of January 2020, more than 5 million people left Wuhan because of the Chinese Spring Festival and the COVID-19 outbreak (disclosed by the press conference held by the Hubei Provincial Government on January 26, 2020). It is very likely that the population inflow to Wuhan was less than the outflow, and the proportion of confirmed cases in the incoming population should be lower than that of those leaving the city, possibly creating higher pressures on the health insurance fund.

In comparing between schemes, the impact of China's COVID-19 treatment policy is apparently more severe on the URRBMI fund. Compared to URRBMI, the UEBMI fund has wider coverage and offers higher benefits, owing to its greater financing capacity. In the sample period, the average funding of UEBMI was 6.44 to 9.42 times that of URRBMI. The average reimbursement rate for UEBMI inpatient costs was between $71.8 \%$ and $85.5 \%$, whereas the URRBMI only reimbursed $65.6 \%$ to $75 \%$ of the costs. To maintain actuarial balance in 2020, the coverage for ordinary medical expenses in the URRBMI system will have to be significantly lower than in previous years, potentially influencing the wellbeing of enrollees and resulting in inequality across schemes.

The integration of URBMI and NCMI into URRBMI in 2016 was considered an important step toward achieving the ultimate goal of establishing equal health care for all. While the 2016 document does not indicate whether the URRBMI will be merged with UEBMI in the foreseeable future, this integration is necessary, especially for strengthening longer-term preparedness and resilience in managing future public health crisis. Closing the coverage gap between URRBMI and UEBMI would require the government to source a huge amount of funds to subsidize the premiums of URRBMI's enrollees, making the integration rather challenging and probably time consuming. Transitional measures, such as a risk equalization fund, injected from tax revenue or earmarked premiums-like what was done in Japan and Colombia ${ }^{7}$ - can be created alongside a multiple-fund system to compensate enrollees with the difference between a standard per capita premium and the full expected costs, adjusted for age, gender, and chronic conditions. This arrangement can help establish necessary connections across schemes and meet the objective of providing an equal benefits package for all insured.

There is also a disparity of capacity between localities. In this research, a current deficit in the URRBMI system may occur in three sample cities other than Wuhan if a public health event of the same magnitude as COVID19 breaks out. Cities $\mathrm{N}$ and X, with lower per capita incomes, are likely encounter worse situation, whereas Cities $\mathrm{H}$ and $\mathrm{G}$ are expected to be robust in the face of such an emergency, even with reimbursement rates as high as $65.08 \%$. Differences in funding can explain part of the disparity. Specifically, the per capita funding of the Wuhan URRBMI fund in 2018-2020 was 740, 760, and 770 yuan, respectively, while that of City $\mathrm{H}$ was between 1150 and 1170 yuan. Going deeper, however, the considerable variance in capacity across regions is rooted in disparities in economic development and fiscal income. Cities in eastern China, such as Cities $\mathrm{H}$ and $\mathrm{G}$, generally have a higher level of economic development and are capable of allocating more government revenues to support investment in health insurance.

Disparities between localities, especially within one province, also have much to do with the municipal and county-level pooling of insurance funds in China. For risk diversification on a wider scale in the face of an emergency, promoting provincial pooling is necessary. In the 2018 institutional reforms by the China State Council, the NHSA was established to take charge of the regulations and supervision of all SHI schemes, and it was entrusted with the task of promoting provincial pooling of funds. The formation of NHSA largely reduced bureaucratic barriers in the vertical integration of pooling funds within the same scheme and province, but equalizing the benefit packages of all enrollees at the provincial level entails tremendous fiscal commitment from provincial authorities to close the intra-provincial gap, which can be particularly burdensome for provinces with huge internal disparities. Closing the inter-provincial gap, which is unlikely to occur until integration between schemes has made considerable progress, would require even more government injections of funds. Thus, in view of the long-term sustainable operation of funds, a higher-level and longer-term adjusting system for the surpluses and deficits among pooling units (even from different provinces) is advisable, which might be especially helpful considering the vulnerability of health insurance funds to withstand sudden shocks, such as infectious diseases that may result in a geographical concentration of cases and difficulty in adjusting insurance 
funds within a particular region-just like what happened in Wuhan and Hubei Province in China during COVID-19.

Besides the consolidation of insurance schemes and funds, the creation of an emergency safety net in the health insurance system is also suggested. Past experience shows that inbuilt counter-cyclical stabilizing and reserve accumulation mechanisms for health system financing can provide a temporary buffer; long-term and stable emergency arrangements will also strengthen the role of the health insurance system as a firewall and stabilizer. For China and many countries, a contingency management mechanism, such as an emergency reserve within the health insurance system, can provide a safety net, and additional government funding, together with other sources of funds, such as donations, can all be utilized to form the emergency reserve, which can be specifically designed to address major shocks.

\section{Conclusion}

It is imperative that health systems globally leverage the pandemic to bounce forward to not only respond to current shocks, but to actively prevent future crisis. ${ }^{26}$ Throughout the world, the role of health insurance systems in responding to COVID-19 and the need to (re-)invest in these systems offer transformative opportunities. ${ }^{27}$ During the pandemic, health insurance systems were expected to deal with the cost issue, as treatment expenses for COVID-19 are covered by public health insurance in many countries, raising concerns about the sustainability of health insurance systems. This study investigates the impact of COVID-19 treatment policy on the sustainability of the public health insurance system in China, where confirmed cases were first reported. The article explores the influence of the COVID-19 pandemic on Wuhan's system using actuarial models of SHI funds, and discusses the impact of emergencies of the same magnitude on SHI funds in five other provincial capital cities in China. The findings suggest a disparity in risk tolerance between schemes and localities. It is very likely that Wuhan's URRBMI fund will suffer a current deficit, potentially influencing the wellbeing of enrollees, while UEBMI will retain a considerable surplus. Similar situations may occur in three of the other sample cities if a public health event of the same magnitude breaks out, and some cities with underdeveloped economies and low per capita incomes are likely to encounter situations worse than that of Wuhan.

The disparity in capacity between schemes and localities is deeply rooted in the fragmented system characteristics of SHI in China. In view of the goal to provide equal healthcare to all, and for the sake of strengthening longer-term preparedness and resilience in order to manage future public health crisis, the ultimate integration of URRBMI and UEBMI is believed to be necessary; transitional measures, such as a risk equalization fund, can also be created alongside a multiple-fund system to establish necessary connections across pools. Moreover, for risk diversification on a wider scale in face of an emergency, provincial pooling and a higherlevel and long-term adjusting system for the surplus and deficits among the pooling units are suggested. An emergency safety net in the health insurance system in the form of an emergency reserve can also be constructed. All of these measures to promote a transition toward a more sustainable and equitable SHI system would call for more political will and public health investments, especially in the form of fiscal injections on the part of the government. These solutions are advocated as a priority in many parts of the world in the post-COVID-19 era.

\section{Abbreviations}

SHI, Social Health Insurance; OOP, out-of-pocket; UEBMI, Urban Employee Basic Medical Insurance; URRBMI, Urban and Rural Residents Basic Medical Insurance; NCMI, New Cooperative Medical Insurance; PAYG, pay-as-you-go; NHSA, National Healthcare Security Administration.

\section{Data Sharing Statement}

The datasets supporting the conclusions of this article are available at reasonable request to the corresponding author.

\section{Ethics Approval}

Ethical approval for this study was not required per national legislation and institutional requirements.

\section{Author Contributions}

All authors made a significant contribution to the work reported, whether that is in the conception, study design, model construction, execution, acquisition of data, analysis and interpretation, or in all these areas. They also took part in drafting, revising, or critically reviewing the article. All authors approved the final manuscript, agreed on the journal to which the article has been submitted, and agreed to be accountable for all aspects of the work. 


\section{Funding}

This study is supported by China's National Office for Philosophy and Social Sciences (Grant Number 21BSH021).

\section{Disclosure}

The authors report no conflicts of interest in this work.

\section{References}

1. Karanikolos M, Heino P, Mckee M, Stuckler D, Legido-Quigley H. Effects of the global financial crisis on health in high-income OECD countries: a narrative review. Int $J$ Health Serv. 2016;46:208-240. doi:10.1177/0020731416637160

2. National Healthcare Security Administration, Ministry of Finance. Notice on the Medical Security of the COVID-19 Infection; 2020.

3. China State Council. Fighting COVID-19: China in Action; 2020.

4. Zhou T. The Role of Government and Market in Health Financing [dissertation]. Shanghai: Academy of Social Sciences; 2016.

5. Hsiao WC. The Chinese health care system: lessons for other nations. Soc Sci Med. 1995;8:1047-1055. doi:10.1016/02779536(94)00421-O

6. Meng Q, Tang S. Universal health care coverage in China: challenges and opportunities. Proc Soc Behav Sci. 2013;77:330-340. doi:10.1016/j.sbspro.2013.03.091

7. Ma J, Lu M, Quan H. From a national, centrally planned health system to a system based on the market: lessons from China. Health Aff. 2008;27(4):937-948. doi:10.1377/hlthaff.27.4.937

8. World Health Organization. The World Health Report 2000-Health Systems: Improving Performance. Geneva: WHO; 2000.

9. Carrin G, James C. Reaching Universal Coverage via Social Health Insurance: Key Design Features in the Transition Period. Geneva: World Health Organization; 2004.

10. Blumenthal D, Hsiao W. Lessons from the East - China's rapidly evolving health care system. $N$ Engl J Med. 2015;372:1281-1285. doi:10.1056/NEJMp1410425

11. Meng Q, Fang H, Liu X, Yuan B, Xu J. Consolidating the social health insurance schemes in China: towards an equitable and efficient health system. Lancet. 2015;386:1484-1492. doi:10.1016/S01406736(15)00342-6

12. Wagstaff A, Lindelow M, Jun G, et al. Extending health insurance to the rural population: an impact evaluation of China's new cooperative medical scheme. J Health Econ. 2009;28:1-19. doi:10.1016/j. jhealeco.2008.10.007

13. Qu TT, Xie NQ, Yi P. Medical insurance payment method reform and the control of medical and drug expenditures. Nankai Econ Study. 2019;5:147-164. doi:10.14116/j.nkes.2019.05.008
14. Li SQ, Chu FL. Impact of the reform of the prospective payment system on medical expenses: based on regression discontinuity design. Chin Soc Security Rev. 2020;3:47-61.

15. He J, Wu S. Towards universal health coverage via social health insurance in China: systemic fragmentation, reform imperatives, and policy alternatives. Appl Health Econ Health Pol. 2017;15 (6):707-716. doi:10.1007/s40258-016-0254-1

16. Jia HB, Zhao DH. Study on the influence of aging on urban employee basic medical insurance funds: based on the evidence of provincial panel data from 2004 to 2015. Shanghai Econ Study. 2017;10:36-44. doi:10.19626/j.cnki.cn31-1163/f.2017.10.004

17. Wang MH, Lu GC. Study on payment method and compensation level of outpatient special medical insurance. Res Health Econ. 2018;377:46-49. doi:10.14055/j.cnki.33-1056/f.2018.09.015

18. Wang Q. Actuarial Evaluation on the Sustainability of China's Basic Health Insurance Fund [dissertation]. Beijing: Central University of Finance and Economics; 2016.

19. Feng L, Yang J. Sustainability of UEBMI system: based on delayed retirement and comprehensive two-child policy adjustment. Res Financial Econ Issues. 2019;429:122-129. doi:10.19654/j.cnki. cjwtyj.2019.08.015

20. Zhou J, He M. Sustainability of basic medical insurance: influence of aging, pollution and policy change. ShangHai Finance. 2019;7:11-20. doi:10.13910/j.cnki.shjr.2019.07002

21. Liu SJ, Huo HJ. Research on forecast of income and expenditure of inner Mongolia urban employee basic medical insurance coordination fund. China Health Econ. 2019;38:34-36. doi:10.7664/ CHE20191108

22. Bo B, Tao WJ. Social determinants of health and inequalities in COVID-19. Eur J Public Health. 2020;30:617-618. doi:10.1093/eurpub/ckaa095

23. De L, Hong Q. The responsibility of health insurance in dealing with SARS. China Soc Secur. 2003;6:38.

24. Huynh TL. The COVID-19 risk perception: a survey on socioeconomics and media attention. Econ Bull. 2020;40:758-764.

25. Huynh TLD. Does culture matter social distancing under the COVID-19 pandemic? Saf Sci. 2020;130:104872. doi:10.1016/j. ssci.2020.104872

26. Victoria H, Garrett TM. From resilient to transilient health systems: the deep transformation of health systems in response to the COVID-19 pandemic. Health Policy Plan. 2021;36:134-135. doi:10.1093/heapol/czaa169

27. Gilson L, Marchal B, Ayepong I, et al. What role can health policy and systems research play in supporting responses to COVID-19 that strengthen socially just health systems? Health Policy Plan. 2020;3:1231-1236. doi:10.1093/heapol/czaa112.
Risk Management and Healthcare Policy

\section{Publish your work in this journal}

Risk Management and Healthcare Policy is an international, peerreviewed, open access journal focusing on all aspects of public health, policy, and preventative measures to promote good health and improve morbidity and mortality in the population. The journal welcomes submitted papers covering original research, basic science, clinical \& epidemiological studies, reviews and evaluations, guidelines, expert opinion and commentary, case reports and extended reports. The manuscript management system is completely online and includes a very quick and fair peer-review system, which is all easy to use. Visit http://www.dovepress.com/testimonials.php to read real quotes from published authors. 